Civic Review, Vol. 16, Special Issue, 2020, 460-472, DOI: 10.24307/psz.2020.1230

Márton Gellén, Anita Mária Rácz

\title{
Motivation and Professionalisation in Hungarian Civil Service - an Empirical Analysis on Hungarian Regional Civil Service
}

\section{SUMMARY}

The article displays and analyses the results of empirical research, in the context of mainstream public sector motivation PSM literature, and in the context of the recent Hungarian legislation on public service personnel management. The aim of the article is to clarify the impact of the new legislation on the motivation of Hungarian civil servants. The findings ought to be interpreted with references to the complexities of practice in Central and Eastern European civil service, widely considered as Weberian, although with significant elements of legalism, politicisation and postSoviet management style. As this public administration culture is heterogeneous and its components are contradicting, changes in public personnel management policies might lead to unexpected or largely vary- ing effects. This article presents the findings of public personnel management policy change through the evaluation of the responses of civil servants in regional civil service. The article concludes that the subjective value of job security is less than expected, but satisfaction with the pay is significantly above expected. Streams for promotion are frozen, good workforce is difficult to retain in civil service but those who remain in the service consider themselves highly motivated, receiving helpful support from their supervisors and feeling that they have a rewarding job in serving the public.

Journal of Economic Literature (JEL) codes: H83, J45, O18

Keywords: public sector motivation, leadership, public administration culture

Márton Gellén PhD, university lecturer, National University of Public Service, Budapest; Anıta Mária RÁcz, PhD student, National University of Public Service, Budapest $^{1}$ 


\section{Academic Workshop}

\section{Public Service Motivation theory IN BRIEF}

Public Service Motivation (PSM) theory was, for the most part, developed by James Perry, who separated motivation, as a certain passion of serving the public, and the general management motivation theory, which was created to meet the needs of the business sector. The main finding of the PSM theory is that staff motivation in the public sector is characterised by significantly different features than motivation in the private sector. Civil servants indeed have very different internal preferences than workers in the market sector. Furthermore, certain motivating factors that are applicable in the business sector prove to be even counter-productive when it comes to the public sector.

Perry et al. (2006) found that financial incentives slightly influence work performance in the public sector but far from being as effective as one would instinctively think. In fact, changing the way of thinking about the effect of financial incentives in the public sector was one of the main intellectual achievements of PSM theory. Stajkovic and Luthans (2003) based their findings on an empirical research of 72 cases, and concluded that financial incentives have 23 per cent impact on work performance while social recognition correlated to work performance by 17 per cent and feedback from the supervisor contributed to work performance by 10 per cent. Any single one of these factors hardly improved performance but if conducted in a combined way, their overall impact was 45 per cent, which can be considered as a significant and tangible performance growth. Bucklin and Dickinson (2001) found that individual financial incentives - such as pay by performance - do have beneficial impact on individual motivation but such incentives are more effective if they are applied in combination with feedbacks from supervisors. Perry et al. (2006), however, insist that this finding was based on research that has a rather low validity in relation to public service.

According to the studies of Milkovich and Wigdor (1991) pays based on performance do have a tangible impact but only if the remuneration policy is embedded into a fair and effective process. The actual feasibility and comprehensibility of the practice followed by any given public institution is almost as important as the potential pay itself.

Contrary to the theorists of public service motivation directed to increase individual performance, Perry et al. (2006) found that group incentives are more efficient than individual motivators. In content, group incentive means that a certain percentage of the pay is tied to the collective performance of a given group, unit of sub-unit. Perry et al. (2006) base this statement on the results of DeMatteo, Eby and Sundstrom (1998) as well as on HoneywellJohnson and Dickinson (1999).

Naturally, there were substantial differences between the research designs listed above but the authors have consensus in concluding that equally distributed, relatively small groups were the most receptive to group incentives.

Work schedule, planning and the organisation of work also strongly correlate with motivation. At this point affective and behavioural motivations need to be differentiated based on the works of Griffin et al. (1981). Perry et al. (2006) agree with Griffin et al. (1981) that measuring work results is much more difficult than measuring workers' satisfaction, while these two factors do not necessarily correspond to each other. 


\section{Academic Workshop}

Civil servants' participation in decisionmaking is anothre important element in public-sector motivation according to Cawley et al. (1998). Gellén (2016) detected a strong desire among civil servants for involvement in public sector decisions. According to Wagner (1994), participation may contribute to better decisions but its causal connection to motivation is limited. Participation is linked to leadership by objectives, which was among the most intensively researched fields in the USA in the 1990's (Mitchell and Daniels, 2003). Setting objectives and motivating personnel towards objectives proved to be difficult a task due to multiple contextual elements that influenced motivation. If objectives are too abstract or too difficult to comprehend, it tends to discourage civil servants and thus often diminishes their motivation (Locke and Latham, 2002). According to Perry et al. (2006), motivation by objectives provides tangible results if the objectives are matched by feedbacks and performance-based remuneration. Desmarais and Gamassou (2014) question the generally assumed high correlation between PSM and hierarchic position. They found that relatively high PSM can be measured even at the lower ranks of the (French) civil service. They explain their finding by an a priori existing altruistic mind-set in civil servants and by the cultural specificity of Francophone countries that civil servants feel rewarded by being able to do something for the public (Cartier et al., 2010).

The correlation between PSM and age (Bright, 2005) and PSM and position in the hierarchy are also discussed by various authors. Naff and Crum (1999) found that PSM slightly increases throughout the long years of the public service career. Perry (1997) also demonstrates this phenomenon and explains it by assuming that there is a higher probability of occupying leadership positions at a higher age, furthermore, merit-based promotion systems tend to select those to higher positions who have high motivation in general.

According to the PSM theory it is an improper approach to assume that general management techniques can be automatically implemented in the public sector. Appreciation and "the ability to do something for others", similarly to "being involved in important things" (Gellén and Kudo, 2015) are nearly as important motivating factors as an appropriate pay.

The motivation to choose a public sector job largely stems from the trust that such jobs are more stable than those offered in the private sector. This perception is, however, increasingly less accepted, and therefore lifelong loyalty and commitment are less typical than they used to be (Bozeman and Ponomariov, 2009). Kölló indicates that relative pay position is the decisive factor to encourage cross-sector mobility (Köllô, 2013). Another chunk of theory has its focus on more subtle factors, which are difficult to detect, such as the principal-employee relationships (Jurkiewicz and Brown, 1998). Instead of searching for a single factor of motivation in crosssector mobility, Ito conducted his research in three clusters of public service, including technical, professional and leadership positions (Ito, 2003). He focused on motivations to apply for a public sector position. According to his findings - based on a sample of 310 Canadian federal administrators - the key motivating factors see in Table 1.

According to Ito's findings (2003), in the case of Canadian civil servants, commitment to the common good or to the agency are not among the top priorities of choosing a public service career. 
Academic Workshop

Table 1: Jack Ito's numeric results on the motivational factors in Canadian civil service, 2003

\begin{tabular}{c|c|l}
\hline Priority & $\begin{array}{c}\text { Percentage } \\
\text { points }\end{array}$ & \multicolumn{1}{c}{ Response } \\
\hline 1. & $89 \%$ & The opportunity just came at the right time \\
\hline 2. & $69 \%$ & $\begin{array}{l}\text { I had the opportunity to practice the profession I have a university } \\
\text { degree in }\end{array}$ \\
\hline 3. & $48 \%$ & Good career opportunities in public service \\
\hline 4. & $47 \%$ & I scrutinized other private and non-profit job opportunities as well \\
\hline 5. & $41 \%$ & Salary \\
\hline 6. & $41 \%$ & I can serve public good \\
\hline 7. & $29 \%$ & The goodwill of the given public agency \\
\hline
\end{tabular}

Source: Authors' own elaboration

EMPIRICAL FINDINGS ON MOTIVATION

in Hungarian CIVIL SERVICE

Hungary is generally considered as part of the Weberian public administration culture. It is also said to be highly legalistic (see Hintea et al., 2006; Hajnal, 2014), while having tendencies towards politicisation (Meyer-Sahling, 2006). Cameron and Orenstein (2012) add the perspective of the near past, claiming that a certain flavour of post-Soviet leadership style is also present in the public sectors of the entire region. Out of the layers of complexities, we consider the Weberian aspect to be the most profound and decisive. Empirical findings on motivation ought to be interpreted taking Weberian legacy as a contextual element.

Empirical research on PSM in Hungarian civil service is not as abundant as it could or should be. Characteristic findings made back in 2016 serve as points of reference to the recent empirical research described in the following part of this article (Gellén, 2016). One might argue that there were substantial differences between the data collection methods of the two research projects, the former conducted in
2014 and the latter in 2019. Such remarks are valid. Still, both research projects were conducted mostly in regional civil service, namely in the ranks of County Government Offices, and both were focussed (in the former case partly) on motivational characteristics in Hungarian civil service.

Figure 1 displays the numerical results of the research on motivating factors in Hungarian civil service.

The original questionnaire was compiled in a way that responses shed light on the reason for choosing a public sector job. According to the 2016 article, respondents $(10,004$ in total) almost equivocally denied that their motivation was based on their salary or on other benefits. On the other hand, intrinsic motivating factors, such as commitment, were rated relatively high.

Rácz collected empirical data at four public administration authorities in the second half of 2019. She approached 31 public administration institutions by electronic questionnaires during the research (supplemented by personal phone calls), however, only four of them agreed to engage in the proposed empirical research. One of the letters of rejection from a public administration explained their refraining from 
Figure 1: Findings related to motivation in Gellén, 2016

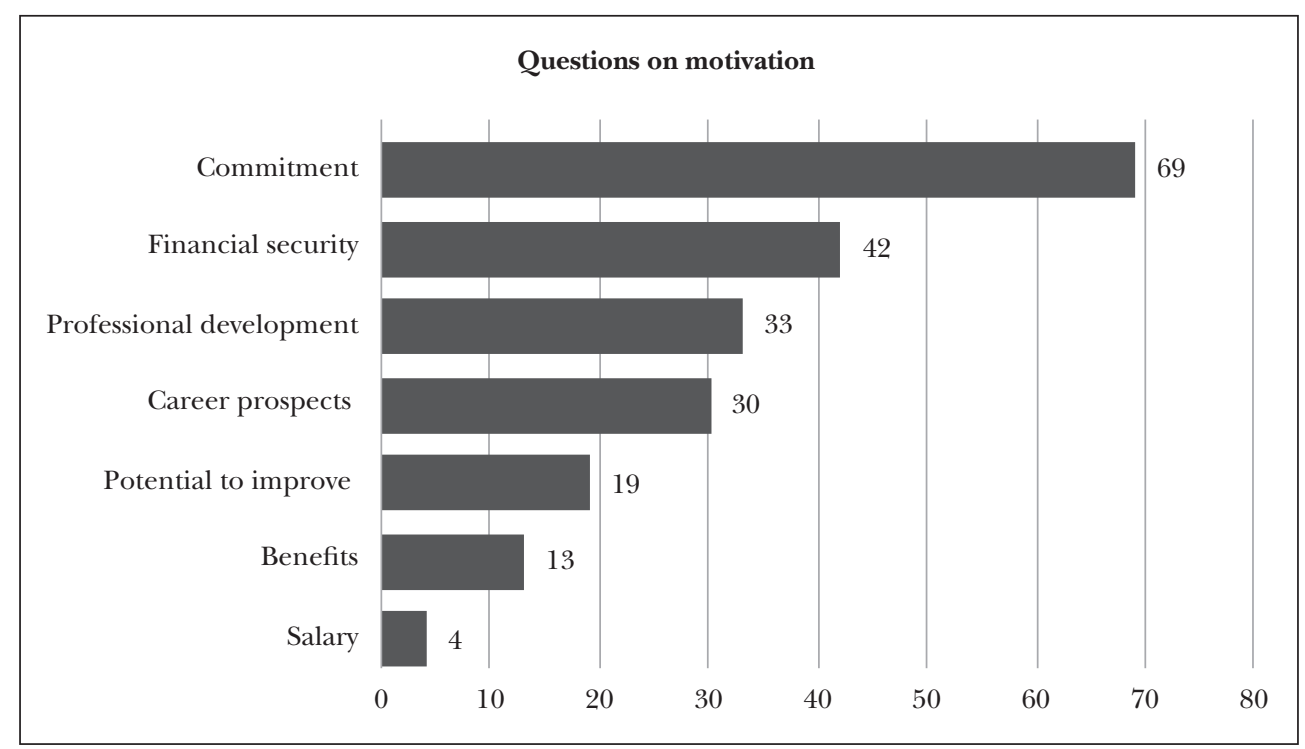

Note: Figures show responses on a Likert scale of 1-5, extrapolated to a 0-100 interval.

Source: Authors' own elaboration

the research by the 2018 Act on Public Sector Staff (Kit.), which cast heavy workload on the civil and public servants, and thus, unfortunately, they had insufficient time and resources to participate in other activities beyond their regular office work. In fact, Rácz's research was conducted at a time when the new act redesigned the landscape of the central and regional public administration in terms of human resource management.

Out of the four respondent authorities, three were County Government Offices and one was an autonomous public administration agency.

As anonymity was guaranteed to the respondents, the public administration institutions involved in the research are marked by numbers. One of the strengths of the research was that the respondents included civil servants in both executive and nonexecutive positions.
The total sample contained 1249 respondents, including:

- 404 respondents from Authority 1,

- 513 respondents from Authority 2,

- 305 respondents from Authority 3 and

- 27 respondents from Authority 4.

The composition of the sample regarding executive positions was the following:

- Top leaders: 16 respondents,

- Directors, heads of divisions, heads of units: 139 respondents,

- Civil servants: 1084 respondents,

- Physical staff: 10 respondents.

The respondents had the opportunity to rate questions on a 6-degree Likert-scale (from 0 to 5 ) indicating 0 as total negation and 5 as total affirmation. The questionnaire contained 38 questions, which suggests a fairly thorough analysis. The Table 2 gives an overview of the responses analysed in more detail. 


\section{Academic Workshop}

Table 2: Summary of numeric results of Rácz's survey on civil service motivation, 2019

\begin{tabular}{|c|c|c|c|c|c|c|}
\hline & $\mathbf{0}$ & 1 & 2 & 3 & 4 & 5 \\
\hline $\begin{array}{l}\text { To what extent does your employer support balance } \\
\text { between work and private life? }\end{array}$ & 4.64 & 4.8 & 8.65 & 22.42 & 30.66 & 28.8 \\
\hline $\begin{array}{l}\text { Evaluate your employer's efforts at retaining good } \\
\text { workforce. }\end{array}$ & 15.13 & 14.6 & 15.13 & 22.74 & 21.62 & 10.8 \\
\hline Does your position offer long-term stability? & 4.48 & 6.81 & 13.61 & 30.5 & 33.94 & 10 \\
\hline Are your duties rewarding? & 0.88 & 3.52 & 6.65 & 20.74 & 44.28 & 23.9 \\
\hline $\begin{array}{l}\text { Can you utilise your professional knowledge and skills at } \\
\text { your work? }\end{array}$ & 1.44 & 2.96 & 8.09 & 17.61 & 40.3 & 29.9 \\
\hline Do you feel motivated in your job? & 6.33 & 7.45 & 11.05 & 22.58 & 34.03 & 18.6 \\
\hline $\begin{array}{l}\text { How good do you think your organisation's incentive } \\
\text { system is? }\end{array}$ & 22.02 & 15.3 & 18.33 & 26.02 & 14.73 & 3.6 \\
\hline $\begin{array}{l}\text { Is your workplace's remuneration scheme competitive } \\
\text { relative to the private sector? }\end{array}$ & 29.46 & 20.9 & 21.78 & 19.14 & 7.45 & 1.28 \\
\hline Is your performance proportionate to your salary? & 15.69 & 17.5 & 19.46 & 25.38 & 18.17 & 3.84 \\
\hline How satisfied are you with your pay? & 15.05 & 16.3 & 19.38 & 25.38 & 20.48 & 3.12 \\
\hline How satisfied are you with your other benefits? & 42.43 & 17.8 & 15.53 & 12.73 & 8.25 & 3.28 \\
\hline How satisfied are you with the number of days off? & 14.81 & 13.6 & 18.09 & 20.18 & 22.42 & 10.9 \\
\hline How clear are the expectations and tasks to you? & 1.68 & 2.96 & 6.97 & 18.17 & 43.55 & 26.7 \\
\hline $\begin{array}{l}\text { How satisfied are you with the professional competence } \\
\text { of your supervisor? }\end{array}$ & 2.48 & 2.88 & 5.84 & 11.29 & 29.46 & 48.1 \\
\hline How much does your supervisor's professional support? & 3.68 & 4.96 & 6.81 & 12.33 & 27.7 & 44.5 \\
\hline $\begin{array}{l}\text { How satisfied are you with the leadership style of your } \\
\text { supervisor? }\end{array}$ & 4 & 3.44 & 6.73 & 13.85 & 29.78 & 42.2 \\
\hline Do you get enough feedback from your supervisor? & 4.96 & 5.75 & 9.21 & 18.41 & 32.67 & 29 \\
\hline To what extent do you feel the symptoms of burnout? & 14.17 & 13.9 & 13.85 & 26.18 & 21.06 & 10.8 \\
\hline To what extent is work stress tolerable for you? & 5.68 & 9.93 & 17.45 & 36.99 & 24.82 & 5.12 \\
\hline Is your professional development supported by training? & 13.13 & 14.7 & 17.13 & 23.7 & 22.58 & 8.81 \\
\hline How important do you think collegiality is? & 0.16 & 0.24 & 0.56 & 3.36 & 21.86 & 73.8 \\
\hline Do you make a good team with your colleagues? & 0.72 & 2.16 & 5.04 & 16.01 & 43.63 & 32.4 \\
\hline $\begin{array}{l}\text { How much does your employer recognise and value } \\
\text { talent? }\end{array}$ & 15.61 & 15.1 & 14.97 & 24.82 & 22.1 & 7.44 \\
\hline $\begin{array}{l}\text { Is it possible to get promotion by merits at your institu- } \\
\text { tion? }\end{array}$ & 22.26 & 15.8 & 18.49 & 24.98 & 15.05 & 3.44 \\
\hline My job motivates me to do my best. & 11.61 & 12.3 & 14.97 & 27.3 & 23.38 & 10.4 \\
\hline Are you satisfied with your working conditions? & 5.04 & 9.53 & 16.49 & 29.38 & 30.42 & 9.13 \\
\hline $\begin{array}{l}\text { How satisfied are you with the motivational features of } \\
\text { the new act on public service? }\end{array}$ & 22.42 & 15.5 & 16.73 & 28.58 & 13.85 & 2.88 \\
\hline
\end{tabular}

Source: Authors'own elaboration 


\section{Academic Workshop}

In the columns of the table the ratios of the respondents choosing the given weight of preference to the total number of respondents are specified. In each column the expected ratio is 16.66 , indicating that one-sixth of the respondents prefer each answer at a particular weight. There are significant extremes both upstream and downstream, and this requires additional explanation.

In order to establish correlation with the briefly indicated PSM theory, the following groups of questions are further scrutinised.

First, the results are analysed according to traditional, external motivating factors, namely pay and job security, and then internal motivational elements are analysed (Figure 4). Leadership and interpersonal motivating factors are displayed in Figure 5 and Figure 6.

\section{ANALYSIS OF THE 2019 EMPIRICAL FINDINGS}

Figure 2 shows the aggregate distributions for the response ratios in a breakdown of questions. Being not overtly satisfied with one's pay is generally normal; therefore the top pay satisfaction category has relatively low support.

Figure 2 allows two characteristic remarks. Primarily, it is apparent that "other benefits" are frustrating rather than rewarding or comforting, let alone motivating. "Other benefits" include the following:

- Contribution to rental fees or to the purchase or construction of a new flat or house,

- Support to young families,

- Social benefit,

- Prepayment on the salary,

Figure 2: Response ratios, remuneration and job stability in Rácz's 2019 empirical research

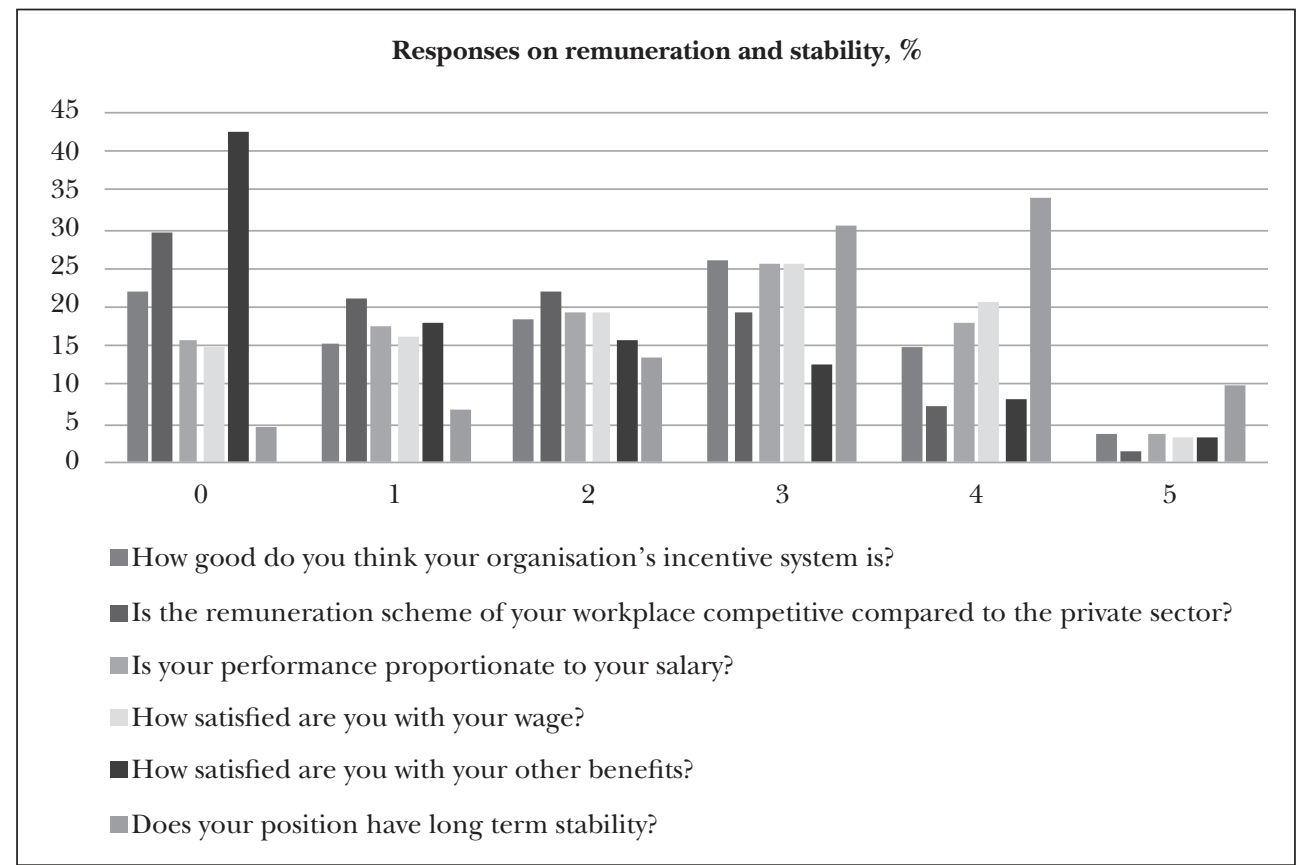

Source: Authors'own elaboration 


\section{Academic Workshop}

- Scholarship, contribution to professional training or to learning a foreign language,

- Holiday benefit.

It is characteristically recognisable that job stability is still highly appreciated compared to other motivating factors. Legal provisions regulating job stability in civil service have undergone significant changes with the adoption of Kit. in 2018. The merit-based - or at least long-term loyaltybased - promotion system has been a decisive characteristic of Hungarian public personnel policy since the early 1990's, when labour law, the act on public service and the act on civil service were adopted. In 2018 (with effect from 1 January, 2019) the previous system of rewarding long-term loyalty with higher salary was replaced by a fixed position system. The overall perception of motivation by the new act is shown in Figure 3.

Figure 3 shows a split between moderate dissatisfaction (3) and strong dissatisfaction
(0) with the motivating features of the 2019 act on public service, after a quarter of a year following its entry into force.

Under the new conditions, a new candidate enters civil service in a given position, he or she remains there until there is an opportunity to take someone else's higher position. Automatic or at least prospective promotion is excluded. Pay rises may be given within the financial framework of the given category. When a civil servant reaches the top position in his or her employment category, there are no further career perspectives ahead. This may be considered as an up or out system in civil service, which is characteristically contrary to the existing and culturally embedded Weberian bureaucratic culture. Despite this legal context, respondents were not concerned about their job stability.

Public sector salaries are apparently seen as moderate but balanced. This however, should be considered a great leap forward compared to the previous research

Figure 3: Scores of the motivation by the new act on public service (Kit.)

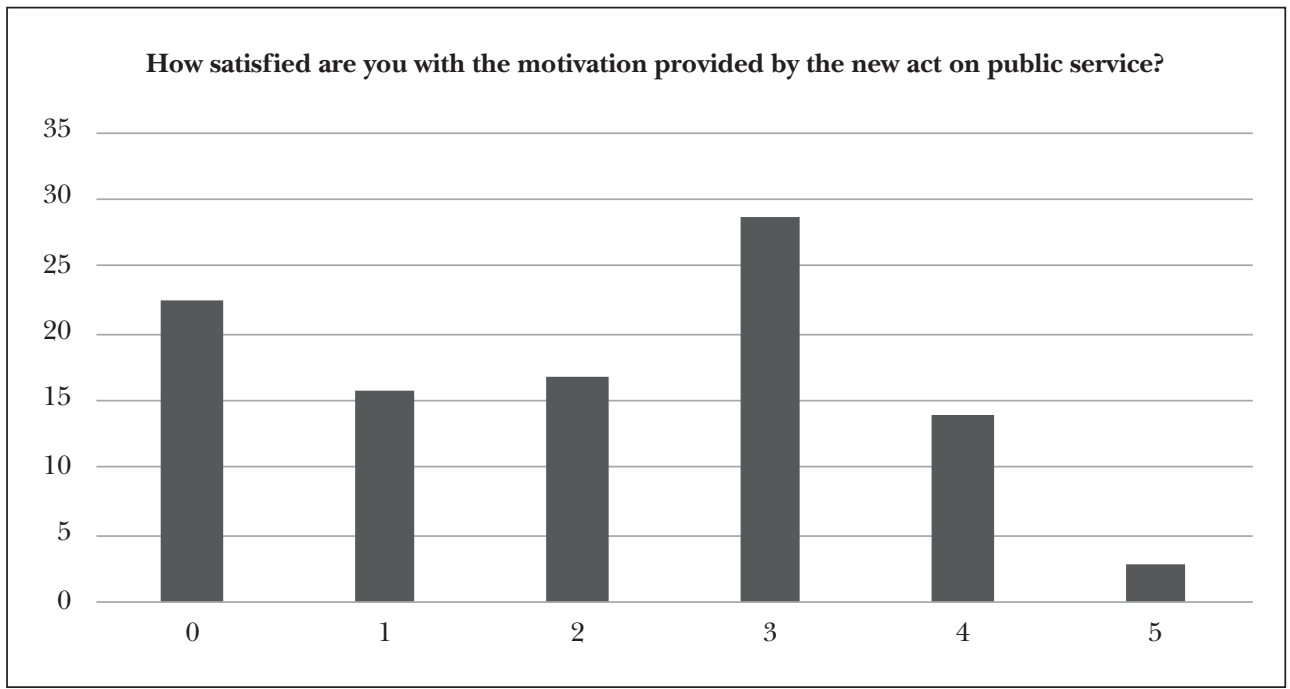

Source: Authors' own elaboration 
Figure 4: Ratios of responses to questions on the internal elements of job stability

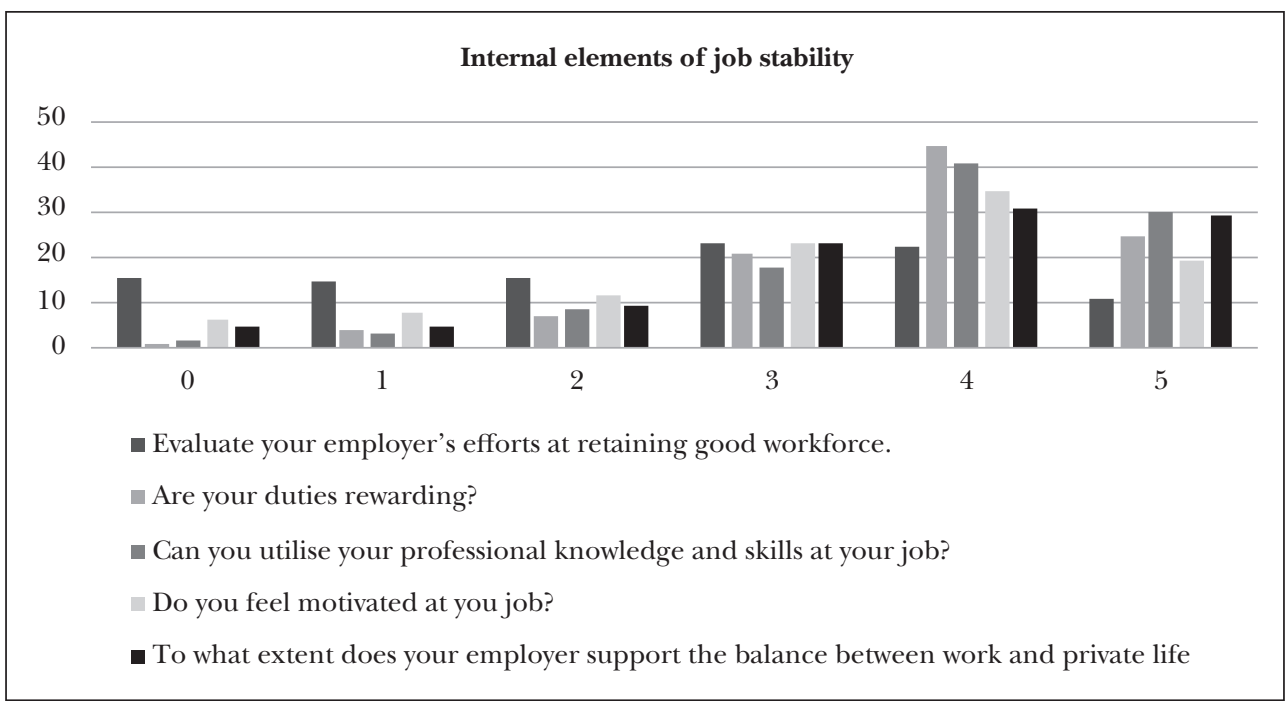

Source: Authors'own elaboration

(Gellén, 2016) cited above. Actually, significant efforts have been made to increase pays in civil service simultaneously with new legislation on employment: pay hikes added up to 30 per cent on average, and must have had a beneficial effect on the respondents' perception. On the other hand, comparison with market wages reflects the common perception in the Hungarian public sector that market jobs are paid considerably better than public sector jobs, although factually this is not necessarily true.

Figure 4 shows the distribution of the ratios of the internal elements of job satisfaction. Employers' efforts - and probably ability - to retain good workforce are relatively ambiguous, with a dominantly even distribution, while the content of public jobs appears to be outstandingly positive (duties are rewarding). Reliance on professional skills, the feeling of self-motivation, and balance between work and private life appear to be characteristically granted. These elements have significantly improved com- pared to Gellén (2016), whereas commitment was characteristically admitted, but all the other factors, such as career prospects, professional development and potential to improve were predominantly perceived by the respondents as non-existent.

Figure 5 displays the ratios of the responses to questions on leadership. Interestingly, the picture is outstandingly positive. At this point (especially regarding the question on supervisor' leadership style), it appears to be legitimate to think of a control bias.

Supervisors' professional competence was also rated outstandingly high. In this case, control bias is even more complex to untangle than with the direct question on the supervisor's leadership style. One of the remarkable results of Gellén's (2016) research was that the Weberian public administration culture embraces professional competence and almost instinctively relates it to leadership and vice versa. According to this bureaucratic mind-set, one is selected 
Figure 5: Distribution of responses to questions on leadership

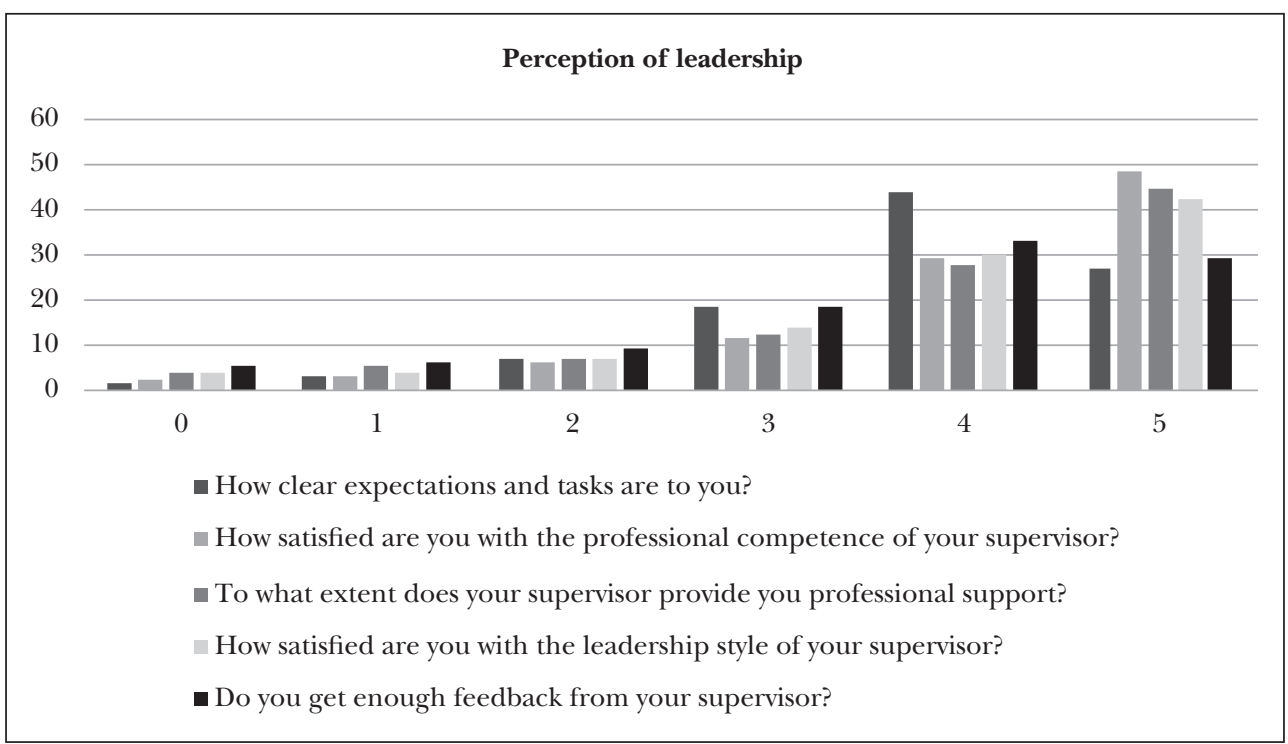

Source: Authors' own elaboration

to act as a leader because of his or her professional competence. Leadership position places the leader in an aura of competence even if professional competence is objectively untrue. This cultural setting matches the directive leadership style (Van Wart et al., 2015) that is fairly exhibited by high scores assigned to the "professional competence of the leader", "professional support" and "feedback from supervisor". If these factors are so highly appreciated by the respondents then how is it possible that the public institutions of the respondents tend not to be able to retain good workforce? It is a legitimate assumption that good workforce is incompatible with directive leadership style, which cannot flourish in the midst of excellent workforce.

Interpersonal motivating factors are somewhat different in Hungary than those described by Perry et al. (2006) as collective incentives in the United States. The establishment of collective incentive schemes by splitting the amount of salary to private and collective portions is unknown in Hungarian civil service. Instead, collective motivation factors are rather related to the subjective value of belonging to a community that shares the same commitment to serving the public or to a given group of clients.

There are two dimensions in interpersonal motivating factors: one relates to horizontal interpersonal relations, namely collegial, peer to peer, intra-unit or intraorganisation relationships, and the other connects the civil servant to upstream supervisors or managers. Figure 6 plots both dimensions. Most remarkably, collegiality as an abstract value scored 73.8 per cent, far more than any other figure in this research. Hungarian civil servants appreciate peer to peer solidarity and collective experience. Interestingly, when it comes to action, their enthusiasm substantially fades. Making an actual good team with colleagues is considerably less supported than the abstract idea of col- 
Figure 6: Ratios of responses to questions on interpersonal motivating factors

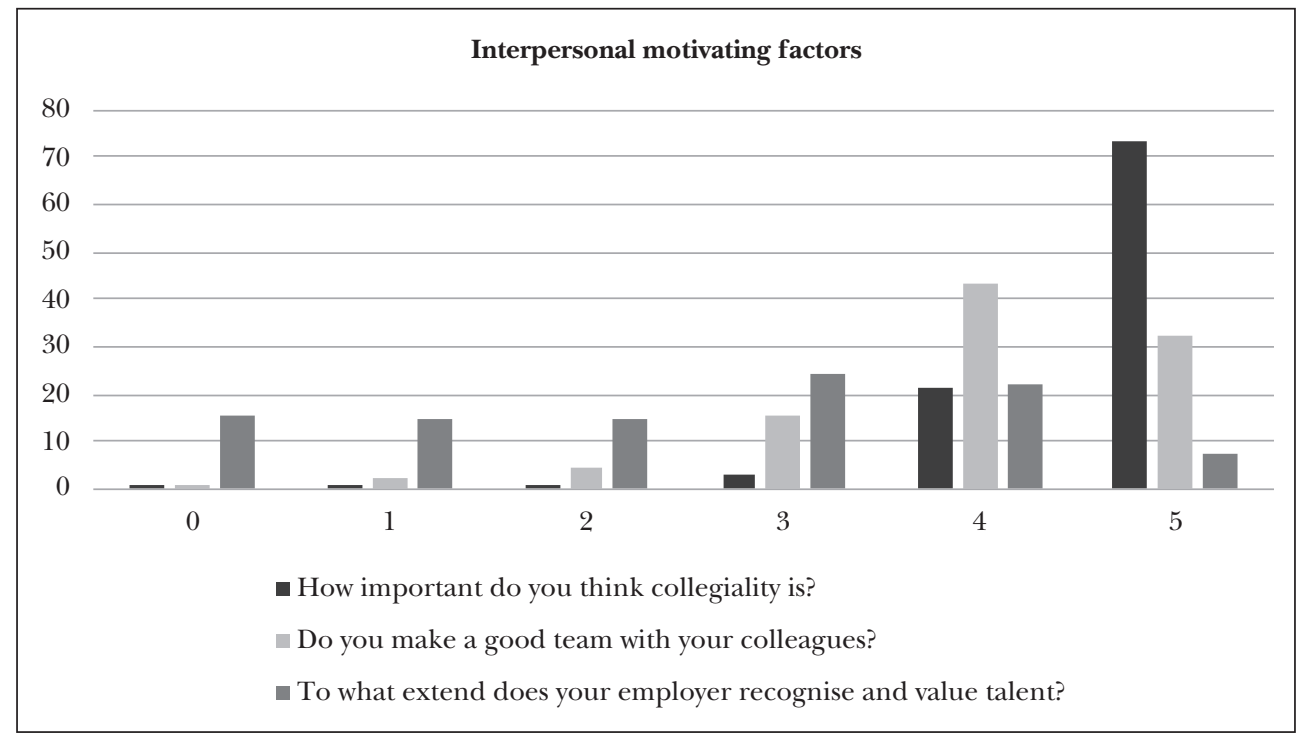

Source: Authors' own elaboration

legiality, although support to making a good team still scores very high compared to the other results in this research. This correlation reveals the two parallel realms of desires and actual experience. The question about the importance of collegiality as a general, abstract concept may instinctively spike pleasant emotions, while directing the respondent to the actual group around him or her might raise doubts in the respondent.

Recognising and valuing talent is an important interpersonal leadership skill, but this factor does not enjoy unequivocal support. In fact, affirmation for this motivating factor is rather ambiguous. How come that the respondents who have previously stated that they are motivated and receive good professional support from their supervisors are so unconfident concerning talent recognition and support from their employers? In our assumption, the answer to this question may be traced back to the previously mentioned directive leadership style that creates the image of a highly competent leader but fails to involve competence and talent from the subordinate civil servants.

\section{Conclusions}

The article has verified much of the general PSM theory but in a different social, cultural and institutional context. According to the current research, slight changes have taken place in the internal characteristics of the Hungarian civil service PSM, which may be attributed to the recent changes in the legislation regulating human resources management in the public sector.

There is a significant improvement in pay satisfaction compared to Gellén (2016). This appears to be obvious, as pays have actually been increased. On the other hand, certain desperation is detectable in civil service ranks, suggested by the limited ability of civil servants to have their talent recognised and appreciated, since the prospect of working 


\section{Academic Workshop}

well and staying in service for a long time, gaining increasing appreciation over time and loyalty is excluded. The internal channels of "organic" development have become limited. Paradoxically, this enhances their hierarchical relationship with their supervisors and enhances the image of the professionally competent, directive leader. What we claim is not that leaders should not be professionally competent. On the contrary. Still, there is much more potential in maintaining motivation in civil service by allowing them feel that they can gain recognition and establish solid careers if they cherish the ambition of their individual development.

The message of collegiality should be taken seriously. The unprecedented high support to collegiality reveals that Hungarian civil servants are beyond the social psychological level of solely individual public endeavours. The research has shown that it is time to endeavour to find collective organisational solutions that would enable the operation of civil service units at a higher level of internal autonomy.

\section{Notes}

1 Anita Mária Rácz is a PhD student at the Doctoral School of Public Administration at the National University of Public Service (NUPS), Budapest. She also works as a HR officer at the Office of Education in Central Budapest, a public institution employing 1,500 people. Assistant professor Márton Gellén is her PhD supervisor at NUPS, and a visiting associate professor at Kwansei Gakuin University, Japan, who also served as deputy state secretary for victim support and legal aid.

\section{REFERENCES}

Bozeman, B. and Ponomariov, B. (2009): Sector Switching from a Business to a Government Job: Fast-Track Career or Fast Track to Nowhere? Public Administration Review, Vol. 69,
No. 1, pp. 77-91, https://doi.org/10.1111/ j.1540-6210.2008.01942.x.

Bright, L. (2005): Public Employees with High Level of Public Service Motivation: Who Are They, Where Are They, and What Do They Want? Review of Public Personnel Administration, Vol. 25, No. 2, 138-154, https://doi. org/10.1177/0734371x04272360.

Bucklin, B. R. and Dickinson, A. M. (2001): Individual Monetary Incentives: A Review of Different Types of Arrangements between Performance and Pay. Journal of Organisational Behavior Management, Vol. 21, No. 3, 45-137, https://doi. org/10.1300/j075v21n03_03.

Cameron, D. R. and Orenstein, M. A. (2012): PostSoviet Authoritarianism: The Influence of Russia in Its "Near Abroad". Post-Soviet Affairs, Vol. 28, No. 1, 1-44, https://doi.org/10.2747/1060586X.28.1.1.

Cartier, M.; Retière, J.-N. and Siblot, Y. (2010): Le salariat a` statut. Presses Universitaires de Rennes, Rennes.

Cawley, B. D.; Keeping, L. M. and Levy, P. E. (1998): Participation in the Performance Appraisal Process and Employee Reactions: A Meta-Analytic Review of Field Investigations. Journal of Applied Psychology, Vol. 83, No. 4, 615-633, https://doi. org/10.1037/0021-9010.83.4.615.

DeMatteo, J. S.; Eby, L. T. and Sundstrom, E. (1998): Team-Based Rewards: Current Empirical Evidence and Directions for Future Research. Research in Organisational Behavior, Vol. 20, 141-183.

Desmarais, C. and Gamassou, C. E. (2014): All Motivated by Public Service? The Links between Hierarchical Position and Public Service Motivation. International Review of Administrative Sciences, Vol. 80, No. 1, 131-150, https://doi. org/10.1177/0020852313509553.

Gellén, M. and Kudo, H. (2015): What Individual Career Strategies Teach Us About Public Administration: A Comparative Study of Japan and Hungary. Conference paper, IRSPM Annual Conference, Birmingham, www.researchgate.net/publication/301684021_IRSPM_2015_Paper_with_professor_Hiroko_Kudo.

Gellén, M. (2016): Potentials for Horizontal Cooperation in a Centralized Setting: Empirical Research on Hungarian Civil Servants' Perceptions on Public Administration Culture. Transylvanian Review of Administrative Sciences, No. 37, 37-53. 


\section{Academic Workshop}

Griffin, R. W.; Welsh, A. and Moorhead, G. (1981): Perceived Task Characteristics and Employee Performance: A Literature Review. Academy of Management Review, Vol. 6, No. 4, 655-664, https://doi.org/10.2307/257645.

Hajnal, Gy. (2014): Public Administration Education in Europe: Continuity or Reorientation? Teaching Public Administration, 11 June, https:/ / doi.org/10.1177/0144739414538043.

Hintea, C.; Ringsmuth, D. and Mora, C. (2006): The Reform of the Higher Education Public Administration Programs in the Context of Public Administration Reform in Romania. Transylvanian Review of Administrative Sciences, No. 16, $40-46$.

Honeywell-Johnson, J. A. and Dickinson, A. M. (1999): Small Group Incentives: A Review of the Literature. Journal of Organisational Behavior Management, Vol. 19, No. 2, 89-120, https://doi. org/10.1300/J075v19n02_06.

Ito, J. K. (2003): Career Mobility and Branding in Civil Service: An Empirical Study. Public Personnel Management, Vol. 32, No. 1, 1-21, https:// doi.org/10.1177/009102600303200101.

Jurkiewicz, C. L. and Brown, R. G. (1998): GenXers vs. Boomer bs. Matures: Generational Comparisons of Public Employee Motivation. Review of Public Personnel Administation, Vol. 18, No. 4, 18-37.

Köllô, J. (2013) : A közszféra bérszintje és a magánszektorból átlépốk szelekciója 1997-2008 között [Wage level in the public sector and the selection of people transferred from the private sector between 1997 and 2008]. Közgazdasági Szemle, Vol. 60, No. 5, 523-554.

Locke, E. A. and Latham, G. P. (2002): Building a Practically Useful Theory of Goal Setting and Task Motivation: A 35-Year Odyssey. American Psychologist, Vol. 57, No. 9, 705-717, https://doi. org/10.1037/0003-066x.57.9.705.

Meyer-Sahling, J.-H. (2006): The Institutionalisation of Political Discretion in Post-Communist Civil Service Systems: the Case of Hungary. Public Administration, Vol. 84, No. 3, 693-715, https:// doi.org/10.1111/j.1467-9299.2006.00608.x.
Milkovich, G. T. and Wigdor, A. K. (eds.) (1991): Pay for Performance. Evaluating Performance Appraisal and Merit Pay. National Academy Press, Washington, https://doi.org/10.5860/choice.29-2194.

Mitchell, T. R. and Daniels, D. (2003): Motivation. In: Borman, W. C.; Ilgen, D. R. and Klimoski, R. J. (eds.): Handbook of Psychology. Industrial and Organisational Psychology. Wiley Publisher, New York, 225-254.

Naff, K. C. and Crum, J. (1999): Working for America: Does Public Service Motivation Make a Difference? Review of Public Personnel Administration, Vol. 19, No. 4, 5-16, https://doi.org/10.1177/0 $734371 \times 9901900402$.

Perry, J. L. (1997): The Antecedents of Public Service Motivation. Journal of Public Administration Research and Theory, Vol. 7, No. 2, pp. 181-197, https://doi.org/10.1093/oxfordjournals.jpart. a024345.

Perry, J. L.; Mesch, D. and Paalberg, L. (2006): Motivating Employees in a New Governance Era: The Performance Paradigm Revisited. Public Administration Review, Vol. 66, No. 4, 505-514, https:// doi.org/10.1111/j.1540-6210.2006.00611.x.

Stajkovic, A. and Luthans, F. (2003): Behavioral Management and Task Performance in Organizations: Conceptual Background, Meta-Analysis, and Test of Alternative Models. Personnel Psychology, Vol. 56, No. 1, 155-194, https://doi. org/10.1111/J.1744-6570.2003.TB00147.X.

Stajkovic, A. D. and Luthans, F. (2006): Behavioral Management and Task Performance in Organisations: Conceptual Background, Meta-Analysis, and Test of Alternative Models. Personnel Psychology, Vol. 56, No. 1, 155-194, https://doi. org/10.1111/j.1744-6570.2003.tb00147.x.

Van Wart, M.; Hondeghem, A.; Schwella, E. and Nice, V. E. (eds.) (2015): Leadership and Culture. Comparative Models of Top Civil Servant Training. Palgrave, Hampshire.

Wagner, J. A. (1994): Participation's Effects on Performance and Satisfaction: A Reconsideration of Research Evidence. Academy of Management Review, Vol. 19, No. 2, 312-330, https://doi. org $/ 10.2307 / 258707$. 